
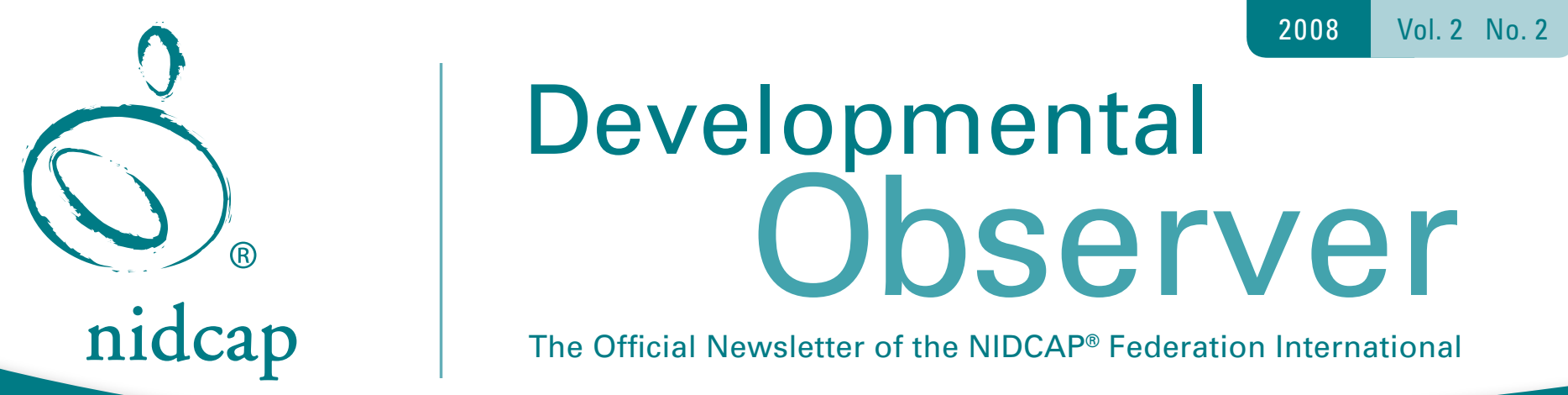

The Official Newsletter of the NIDCAP ${ }^{\circledR}$ Federation International

\section{NIDCAP Federation}

International (NFI)

Founded in 2001, the NFI is an international, non-profit membership organization. The NFI encourages the implementation of developmental care and assures the quality of the Newborn Individualized Developmental Care and Assessment Program (NIDCAP) approach in all intensive and special care nurseries around the world. The NFI serves as the authoritative leader for research, development, and dissemination of NIDCAP, and for the certification of trainers, health care professionals, and nurseries in the NIDCAP approach.

"Courage is what it takes to stand up and speak; courage is also what it takes to sit down and listen."

Winston ChuRchill

\section{Table of Contents}

Family Voices. 1

Message from the NFI President ............ 3

NIDCAP Training Centers from Around the World. 7

The Neuroscience of Skin-to-Skin Contact.. 8

NIDCAP Reflections. 10

NIDCAP Profile 12

Supporting Families... .13

Current Developmental Research........ 14

Developmental Resources . 15

Letters to the Editors 17

\section{Family Voices}

\section{Donnisha McCadden \& Gary Boyd}

Donnisha McCadden has had three pregnancies. The first two led to the birth of three extremely early born infants, who were too young to survive. Then one year after the second pregnancy, Donnisha and her partner, Gary Boyd, were expecting another set of twins. Their story was gathered from telephone interviews.

\section{The Pregnancy and the Birth}

DONNISHA: I found out I was pregnant very early on. I was maybe around four to six weeks pregnant. I got the cervical circlage around three months. My doctor took me out of work. As the babies started to gain weight, lying around all day became strenuous. However, I did it.

GARY: Donnisha was pregnant with twins and we had a test in the hospital where they stuck a needle down in her belly and took some amniotic fluid. Gabby was supposed to be the one that had the worst possibility of making it. They were talking about a whole host of things that could have been wrong with her. The baby that was positioned lower in the uterus, her brother Gavin, was fine. No issues whatsoever. So we were most concerned about Gabby. Tenfold.

DONNISHA: When the babies actually started to get heavy is when the premature labor started for me. I went into labor on December $27^{\text {th }}$, two days after Christmas and the doctors and nurses did everything they could to stop it and it actually stopped. Maybe a day or two later, I got transferred to Cooper University Hospital (in Camden, New Jersey) and the doctors gave me magnesium (sulfate) to stop my labor and it finally worked. So I stayed in the hospital actually for a week and that was a good thing. I think that, that week, I was happy because I was like okay "I can do this, I can do this, I can do this." Then the circlage started to

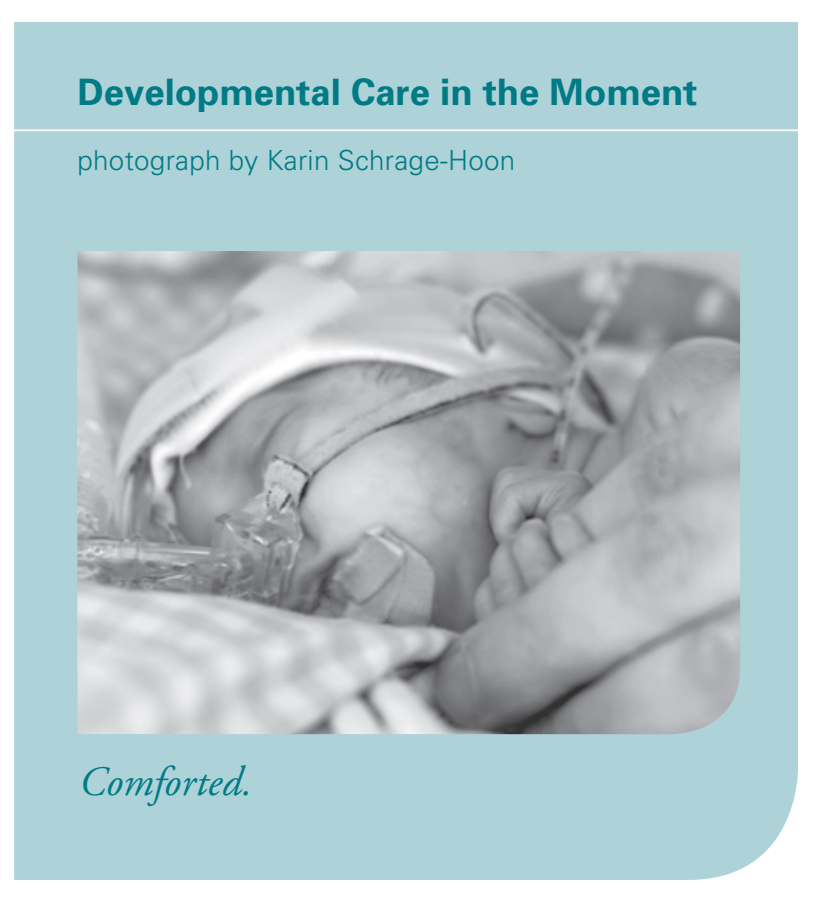


break and open and they needed to take it out. When they did take it out my water broke, however, I still didn't go into labor. They thought that Gavin was going to come out but he didn't, they both stayed in. And I was happy about that. Very happy. Then an infection set in, and that caused me to go into labor. However, it was a week later, thank God.

The birth for Gabby and Gavin was very stressful because of how intense my labor was and how fast it progressed. I started labor in the wee hours of the morning, maybe three o'clock. However, the nurses were checking on me because they realized I had a fever that kept going up. I wasn't telling them that I was in labor, I just kept moaning because I was trying to hold them in as long as I could. Gavin was born at ten something and Gabby was born an hour later.

GARY: When Donnisha was in the hospital she caught an infection and it infected my son. He didn't make it.

DONNISHA: Gabby was one pound six ounces and she was born at 24 weeks. She had just turned six months to the day when I had her and Gavin. It was very stressful. She was actually coming out in her water sack. I remember, that her dad said when we got to the end, she tried to open her eyes but she couldn't she was too premature but she did try... My birthing experience was not a pleasant one, not for me.

\section{The Newborn Intensive Care Unit}

DONNISHA: Well... the ever-going roller coaster that they say happens, it definitely happened. First week, first three to four days, Gabby seemed fine, no problems, she needed a little bit of oxygen, then we went down the roller coaster with her catching an infection. They were trying to feed her, and then she had green (stools) so they gave her antibiotics. Then Gabby starts to progress with her eating, then we go back down with her eating through the tube. And then we go back up another roller coaster and then we go down with an infection, her blood culture is not

coming back correctly. It was a trying time. Then Gabby had jaundice. It was just a lot. It was just a lot to see how small she was when she was born that young. She was very, very tiny. Her skin was transparent. Honestly, looking at her now and then, it's been remarkable. It's a remarkable change. She is totally Gabrielle. Totally her own person now. A totally different person now.

Not only was her medical course a roller coaster, but it was also a very emotional roller coaster. Your emotions are high and then they are low, then they are high and then they are low again. It's a very stressful situation to be in. However, you have to do what you have to do. You can't just look at their little bodies and say "oh well," and then you don't come, you don't visit them, you don't sit with them, you don't talk to them, you don't hold their little hands, you don't participate in the day to day care. I feel that would make them decline as far as their health and their getting bigger and growing stronger. That's my opinion.

I was there as long as I could be there. In the beginning, I would go and stay there all day, until eight or nine o'clock at night. If the doctors were coming and doing rounds or a change in shift, I could basically tell them what happened. That's how much I was there. Gabby had this, this, this, that and the other; this is up, this is down. I could do that. Gabby needed me. Because of her prematurity, she still needed the warmth from me. And honestly, I kangarooed as much as I could. I was a nervous wreck in the beginning because she was so small. Her dad kangarooed when she was almost two pounds. I was so nervous about doing that because, I just felt like she was so tiny. I couldn't do it, but her dad did it. And afterwards, I got used to it.

I felt like the doctors and nurses were my family. You cried, they cried. It was like one big family all the way down to the receptionist. It was nice. The head doctor, Dr. Stahl, was wonderful. In my eyes it is amazing to me, because so much individual attention normally doesn't happen. If I was just going to the hospital on a regular visit, I'm not going to get to see the head doctor. That was very supportive in my opinion. The doctors and

Continued on page 5

\section{Developmental Observer}

A semi-annual publication of the NIDCAP Federation International (C) 2008. Articles from Developmental Observer, duly acknowledged, may be reprinted with permission. Please contact us at: developmentalobserver@nidcap.org.

$\begin{array}{ll}\begin{array}{ll}\text { Senior Editor } \\ \text { Associate Editors }\end{array} & \begin{array}{l}\text { Rodd Hedlund, MEd } \\ \text { Deborah Buehler, PhD } \\ \text { gretchen Lawhon, RN, PhD }\end{array} \\ \text { Text Editor } & \text { Sandra Kosta, BA }\end{array}$

Printed on recycled paper

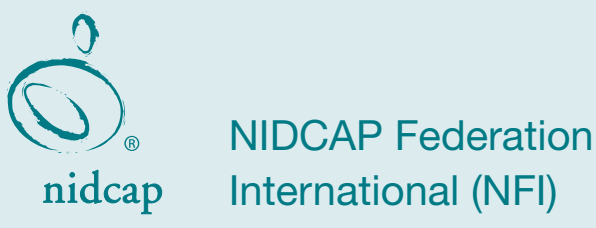

Contributions

We would like to thank all of our individual donors and the following foundations for their generous support of the NFI and its continuing work:

A.L. Mailman Family Foundation

Bella Vista Foundation

Pritzker Early Childhood Foundation 


\section{The Courage to Trust}

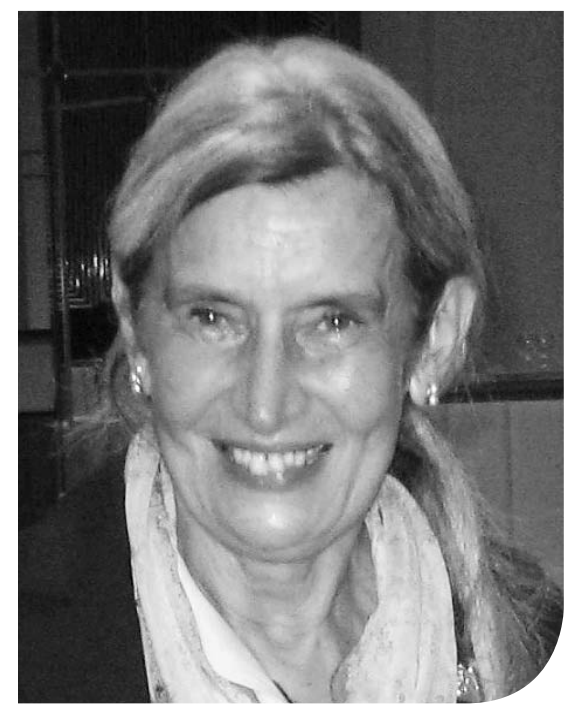

Wisiting a relatively wealthy North African country, I had the opportunity to visit the capital city's University Children's Hospital NICU. I stepped into a barren, grey, factory-like open hall with cold fluorescent ceiling lights over metal cots and large, bulky milky-plastic incubators lined up along a seemingly endless long wall. Shrill alarm, pager and telephone sounds incessantly pierced the air. I had come with high expectations. Suddenly I felt transported back to the NICU-world of the 70's in the United States. Despite the Internet and on-line worldwide access to many professional publications, and numerous international medical congresses, thousands of emaciated and limp infants, clad only in huge plastic diapers, still lie on their backs, depressed and alone in many countries and cities all over the world. Newly admitted infants, arching and protesting their treatments and abandonment quickly become subdued by relentless routine intensive care that emphasizes equipment and antiseptic procedures above all else.

It is difficult and painful to remember that just 30 years ago most NICU care was like that. Only professionals were admitted to the Unit. Loudspeakers overhead incessantly announced lectures and doctors' pages from anywhere in the entire hospital. Cleaning buckets and buffing machines, and those who operated them, merrily entered the NICU at any time. Staff members, well intentioned, called to one another from the entrance door to the farthest incubator's nurse and doctor.

The understanding we have gained over the past three decades in reading the infant's language has made it increasingly clear that the parents are quintessential and critically important to ease the infant's often abrupt and unexpected transition from the womb to the NICU. We have learned that parents are the best medium for healing and development. Gradually parents' presence has become increasingly familiar to the technically trained NICU staff. Early on, parents were often relegated to standing at the incubator for short periods of time, as they gradually gained the trust of the staff that indeed they know and care deeply about their infant. Yet they also dutifully leave when the messages (whether spoken, in gesture, explicit in the emotional ambience, or the physical environment) tell them that they have outstayed their welcome. Often the parent booklet they receive states explicitly that they are invited to come at any time, 24 hours around the clock. Yet, still today in too many NICUs, even in those with individual family rooms for each infant and family, it's still a struggle for staff to live up to their own best proclamations. The mother or father who comes to be with their infant at seven o'clock in the morning and reluctantly leaves at eleven o'clock at night, may still today, in a modern NICU, be described as "controlling" and mistrustful of the staff's skill and caring. Much staff education, emotional support and guidance is still required to effectively enhance staff confidence and trust to truly value the parents as collaborators and their infants' foremost caregivers, nurturers, and life-long safe havens. Less psychologically demanding innovations over the last 30 years have become standard care by now in many US and European NICUs (e.g. all infants have nests and many incubators are covered; everyone appears to know about the importance of nonnutritive sucking, of support to midline positions, and of the values of skin-to-skin holding or kangaroo care). The bigger step is the astute appreciation of each infant's thresholds to stress and the conclusions to draw from this recognition for the individualization of care and experience for infant and family, including: the slow pacing of care; feeding only while holding the infant; support to falling and staying asleep while held for prolonged periods; and the many subtle aspects that truly enhance an infant's competence and reduce stress. While everyone is concerned about brain growth and nutrition, the way the nutrition is delivered and received by infants still poses a challenge. The infant's active partnership in all care collaboration, the only way that care may become effective as intended, is a continued and active topic for staff education.

The situation becomes startling when all of the considerations are still below the threshold of conscious staff awareness: a NICU where mothers come reliably every morning to bring the milk that they have pumped at home for their infants and pass it through a small window to an anonymous hand on the other side; where parents come every day at a fixed hour in the afternoon for 10 minutes to stand in a dilapidated corridor and look into the NICU through a dirty, milky, scratched glass window, to see only the incubators and perhaps catch a glimpse of their infant's feet as they extend toward the foot end of the incubator; or hear an infant, maybe their own infant, cry with no one to attend to and comfort the upset child; where nurses with sad, yearning eyes wistfully care for their forlorn charges 
with little hope to find understanding from their leadership; and where money is spent on technical innovations yet is not available for pacifiers, blankets, chairs, and support and education to nurses and young doctors, who are still hopeful and seek to make a difference. Every day the staff cares for the smallest and sickest infants, every day they sustain the pain of their forlorn charges, their emotions and creativity held down, restricted and bent to the rules that govern the system from the top. When death is almost hoped for and is the likely future of a preterm infant; when families are left to their own devices for rehabilitation and care should their infant survive the NICU; when even those with minor disabilities can expect a future fraught with difficulties; then NIDCAP and the NIDCAP stance and spirit are very much warranted as critical care components within the hospital system.

NIDCAP, a systems approach, helps bring about systemic change, not only NICU and hospital system change, but also societal and political system change. Each infant and each family count. Each infant and each family are valuable. But where to begin? Anywhere is better than not at all: one infant and one family at a time; one nurse and one doctor at a time; one NICU and one hospital at a time; one city and one country at a time. This is the only way to create the necessary change.

The medical visitors to this NICU were taken "on tour by the medical director," while the nurses stepped out of the way. As there were no explicit rules for psychologists, I took the liberty to look and smile at the nurses. They gathered quickly around me, and despite our language barrier, they clearly were eager to learn why I was there. In just a few minutes we stood together at a bedside and watched a little boy, who was severely growth restricted, lay flat on his back, flailing his arms, his shoulders retracted and pulled high up to his ears. He arched and screamed in utter despair with his mouth wide-open, ashen grey despite his arousal. I gestured that he might enjoy being tucked in and have something to suck on. The nurses shook their heads in sadness. He was not allowed to eat now. I tried to convey that sucking might help even without food. They looked at me, incredulous. They had never heard of pacifiers and the hospital had none. With gestures and mime, one nurse understood the concept and went to fetch a nursing bottle. We fashioned a pacifier out of the nipple and stuffed it with a piece of cotton cloth. "Now what?" they seemed to ask. When I then supported and guided one of the nurses to open the incubator and gradually place her hands around the infant's feet and legs and speak to him softly, then gather his hands in her hands, this helped his shoulders to relax, and he gradually looked at the nurse and calmed somewhat. When I now guided her to help him onto his side and to cradle him with her right arm, she spontaneously, with her left hand, supported his grasp, and all the while she spoke very softly to him, her eyes became shiny, her face soft and caring. The other nurses stood and watched, astounded and taken by the little boy's visible transformation in interaction. One nurse went to get some more of the cotton cloth and we made a soft cradle roll to support the little boy along his back. The nurse engaged with him, gently took the makeshift "pacifier" we had made, and held it close to the infant's lips. While still crying softly, he grasped the pacifier with both hands and pushed it into his mouth, sucked like fury, and looked with wide eyes directly at his nurse. She in turn was glued to him and kept her eyes on him. Her hand cradled his body and she slowly covered him gently with another cloth that her colleague miraculously produced. The little boy gradually calmed and drowsed off to sleep, as the pacifier dropped out of his slightly parted, relaxed lips. Very gently the caregiving nurse pulled her hands one by one out of the incubator and softly closed its doors. Her face, her posture and her whole being had changed, becoming soft, fluid, and caring. The nurses crowded in on me. How can they learn more? How will they convince the doctors to help them learn more? How will they bring in the mothers and fathers? The bravest of the nurses, who had just helped the little boy, confided with tears in her eyes that she had smuggled the father of one of the infant's into the NICU several times in the evening, when she felt it was safe. She had observed what it meant to the infant to have his father talk to him and even briefly hold him. No wonder she was so open to try the next step under the guise of my visit.

This is but a tiny yet important seed in the beginning of a garden. I am convinced that with the courage to trust in ourselves, in the infants, in the parents and the staff of nurseries everywhere, we will multiply trust, courage, creativity, and generosity and the effectiveness to bring about change on behalf of infants, families and professionals in intensive care everywhere. Political agendas are made and carried by people. People all share in the same basic human heritage of empathy, caring, and responsibility for one another. NIDCAP must be a spark and an initiative that helps make the thousands of seeds of opportunities, to swell, sprout, and grow, even when seemingly buried deep in arid soils. Together we are strong and will continue to forge an agenda of national and international change and growth.

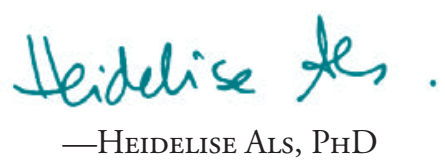

$4 \cdot 2008 \cdot$ Developmental Observer 
nurses acted in my place for me when I couldn't be there. Her primary nurse, Pat, was excellent. All the nurses knew Gabby. All the nurses knew me. I just will never forget these people. They made such an impression on my family and me. The honesty that they provided was especially helpful. Say for instance, Gabby was not having a good day. They would tell you that "This is not a good day for Gabby. Her cultures came back with an elevated white blood cell count. She hasn't been breathing on her own. Her oxygen level had been turned all the way up. She has only been breathing at $85 \%$." Some nurses would just lay it down for you straight. However, during those times her nurse would stay there and would not leave until she felt comfortable enough to leave Gabby with another nurse to take over. So like I said they went through it with you. Everyone worked together.

Unfortunately she still wasn't able to breath on her own for a long time. Being on the oscillator is a scary thing. Gabby progressed backwards. As she got bigger then she needed more oxygen, more for her lungs to open up. That was a scary experience. You would come in, the baby vibrating, the machine vibrating. One day it's turned up, the next day it's turned down. Very scary. Then also, because they're so tiny, they're not able to find veins as quickly as they can on a bigger baby. There were days when I would come in and Gabby would have a needle in her arm, but that vein would soon collapse and the nurse would have to find a vein in her other arm. It was like: "Oh man, you just keep sticking my poor baby.”

My experience at the Ronald McDonald House was also wonderful. There was another parent, whose daughter was born two days from Gabby. We went through this whole ordeal together. We would call each other. "Hey, are you going to the Ronald McDonald House this weekend? "Yes." We would connect there. We would go sit with the girls. Hold the girls. Do whatever we needed to---Kangaroo. My experience was just so wonderful. I don't know how else to describe it. It was just beautiful.

After awhile, it got to the point where I was sort of like the lead parent for the new parents in the nursery. I would tell them: "You know you are going to go through a roller coaster and trust me you are going to have your ups and downs. Don't pay attention to the oxygen monitors because sometimes if your baby makes a sudden movement it may kick the lead off. When that happens the monitor will go beep, beep, beep. If you go through that, and if you are by yourself, and your family is not there to support you......you need someone to talk to...... a shoulder to lean on..... a shoulder to cry on. I tried to be there for parents. I guess that's my nature. I always kept other people in my thoughts, and their families in my thoughts, and their child in my thoughts. As I prayed for Gabby, I prayed for others too."

\section{Life at Home}

GARY: When Gabby first came home it was very interesting because she came home with a monitor. So it's one thing to be in the hospital and be there with a monitor because you sort of become numb to all of the bells and whistles. When you're at home with a monitor that's a different experience. It would go off sometimes for basically no reason at all. We hated it. Luckily she wasn't on it long, but it was an adjustment. To be honest with you, Gabby isn't like a lot of others because she slept through most of the night. Maybe once or twice we woke up at two or three in the morning to feed her, but for the most part, she slept through the whole night. It was a blessing. When she slept through the night then we could sleep at night, and then during the day, we took turns caring for her.

Gabby can be a handful. When you are alone with her, you have to keep up with her, because she'll be into a whole host of stuff. The hardest part right now is catching up with her! She's all over the place. She really is into everything, but it's great. The most rewarding part is knowing where she came from and how hard it was for her and how much she had to fight and where's she's at now.

DONNISHA: Gabby is such a daredevil. Everyone at Cooper basically said that she was going to have a feisty personality. Even as a baby, even when she was that small the staff would say: "Oh Gabby is going to be something." And Gabby is something. Now, Gabby will jump off the couch and bed. Gabby has lots of personality. And they said that at Cooper. In the beginning, all she could do was grunt. Premature babies grunt a lot. Even with all the grunting she did her personality shined through. And it kicks out definitely now, because she is talking.

It really was a joy to watch the things that she did. And watch her develop and watch her get bigger. We were blessed to have Gabby, as sparkling as she is... and with as much personality as she has.

GARY: Right now it's been difficult to get her to learn potty training. It may take some time. But really that's not even a complaint, its just part of the process. I only went to work for part of the day when she was younger. Then as she got older we started sending her to a daycare school with the other kids. There she advanced even more, she picked up so much from them. When they say children's learning is like a sponge, Gabby is like a sponge. She repeats everything you say and mimics you and she learns. She learns very fast.

I have a son who is fourteen and a daughter who is eleven. Gabby sees them all the time. They love her and she loves them even though she has started to drive them crazy. That's her job. 


\section{What We Learned}

GARY: Learn as much as you can so you can make informed decisions about your child's care. I think that's very important because sometimes we had to make decisions about whether we wanted this or that. There was a point around eleven days where Gabby didn't eat, the doctors and nurses were trying to figure out certain things about her care, and they were giving her all of her nutrients she needed but she wasn't eating. After a while, I said, "wait a minute she's not eating and I have a problem with that." If you have a question, ask the doctors and nurses. Get to know your nurses because the nurses are extremely important. The doctors come around, they make their rounds, they make their medical diagnoses and then they're off to the next thing. The nurses are there providing that intimate care, that intimate bond all the time. So you get to know the nurses because they will share with you how your child's doing on an every day level. The nurses tell you the baby responds this way when you get close or hold her. The baby likes this or the baby likes that or she was up all night. A nurse will tell you when people were coming in or out of the room, or whether Gabby perked up or she looked up, or she let us know that she knows that she hears us, or whatever the case may be. So these are things that are important because you need that reinforcement when you go to be with your baby and go to hold her. You want to make sure that you establish that bond yourself. So learn as much as you can.

The best thing to do is to have as much information as possible. Gabby got to the point where I told Donnisha one day when we came home "when Gabby gets better you'll know because she'll pull that respirator out of her mouth." The next day, she did pull that respirator out of her mouth. She did it twice and Gabby got better.

DONNISHA: Listening to the doctor and participating with your child's care is important. The more connection you have with your child, the stronger he or she will become. The more time you spend with your baby, the more you do your kangarooing, the more you participate with their care....this will help a lot.

Make sure that you do provide the baby with breastmilk, because that's the best milk that you can provide for them at that time. Eventually Gabby latched on and it was the most wonderful experience. It was soooo beautiful. Sooo wonderful. It really was. Even her dad would say: "You've got to go pump for Gabby, you've got to go pump, you've got to go pump." Towards the end it became difficult because she wasn't there to make the milk come strong. So although I was pumping, it still wasn't the same as her suckling and pulling it out. I went back to work in the process and it became difficult.
Also, you have to have family; you have to have that support system. If you don't have family to help, seek support by networking with other parent groups. There are various groups and organizations that can help assist you in your time of need. Especially at Cooper, the nurses make the experience in the nursery more like a family than anything else.

\section{Wishes for Our Daughter's Future}

GARY: Everything in the world. Everything! It's kind of difficult.....knowing where she came from and seeing her in that itty-bitty bed with red skin. She's chocolate brown now but her skin was bright red then because her skin color didn't come in yet. Just remembering that.... I wish the world for her. I wish the world for her. Any and everything she wants to do.

DONNISHA: To have a prosperous life. I wish for Gabby to strive for anything and everything that makes her happy. Whatever goals she wants to attain, I will be there to help her. I will help her attain her goals because Gabrielle is still a fighter. It's surprising to me that the nurse at Cooper said: "This one's feisty." Gabby's still the same way. She's five times more feisty because she's growing and is bigger now. I wish for Gabby to attain any goal that she wishes to and mommy will be there to assist her and daddy will be too.

—Interview by Deborah Buehler, $\mathrm{PhD}$

\section{Developmental Care in the Moment}

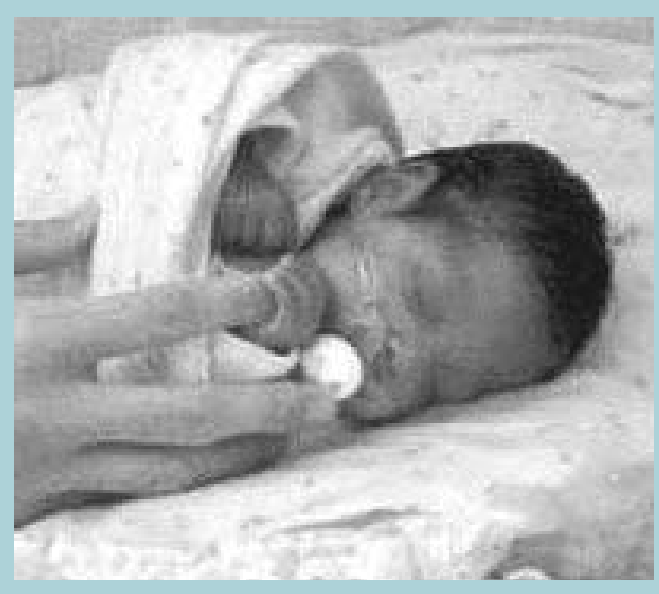

Holding on to one another. 


\section{The French NIDCAP Training Center Experience:}

\section{8-2008: The first decade in Brittany}

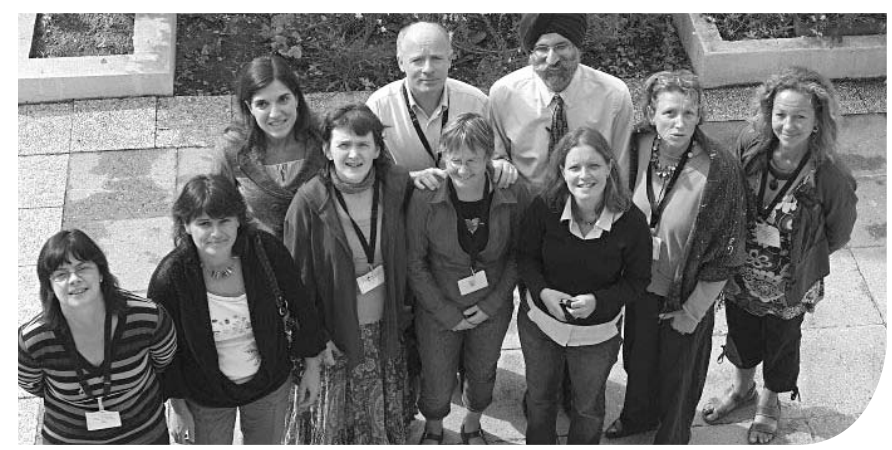

The Brest NIDCAP team: Sylvie Minguy, Isabelle Lohou, Blandine Le Guen, Jacques Sizun, Béatrice Kerleroux, Nathalie Ratynski, Catherine Delage with Professor Anand (University of Arkansas for Medical Sciences, Little Rock, Arkansas, USA), Céline Catelin (former fellow in Brest, France, now a neonatologist in Sherbrooke, Quebec, Canada), and Tiziana Testa (resident in Turin, Italy and Brest, France).

Tn May 1998, a small group of NICU staff (Catherine Mambrini, head nurse, Nathalie Ratynski MD and Jacques Sizun MD) flew from France to Denver, Colorado to begin NIDCAP training. The training and extended discussion with Joy Browne were so positive that this core group decided to go on with NIDCAP implementation in Brest. This trip was also an opportunity to meet the Brussels team from St. Pierre Hospital and reflect on the best implementation strategies for Europe.

In November 1999, Nathalie and Jacques attended their first NIDCAP trainers' meeting in Vermont-- a cultural shock! Moving from the medical to the developmental perspective entailed a continuous reflective process as individuals and as a group. The American welcome was unforgettable and meeting the Swedish team was a great support.

Nathalie Ratynski completed APIB certification in 2003 with Deborah Buehler, as her APIB trainer, and became a NIDCAP trainer in 2004 with Joy Browne as her master trainer. The French NIDCAP Center in Brest opened in July 2004. It was the second such center in Europe and at that time the first French-speaking center. Training began first in the NICUs of Valenciennes, France, and then in the university hospital NICUs in Toulouse, France and Tivoli, Belgium. Training then continued on to university hospital NICUs in Montpellier, France, with ever growing numbers of hospitals requesting future training.

Since the beginning of our NIDCAP work, the creation and development of the French NIDCAP Center was supported by the Dean of the Medical School and the Director of the Hospital. In order to integrate the NIDCAP training with an academic perspective, the French NIDCAP Center was created within the University Department for Continuous Education and Training. This department is in charge of the administrative components of NIDCAP training (contracts with hospitals, invoices, etc.).
The French NIDCAP Center is affiliated with the University Hospital and the Université de Bretagne Occidentale. The Woman, Mother and Child Department, directed by Professor Jacques Sizun, has a referral perinatal center with 2500 deliveries per year and a Pediatric and Neonatal Intensive Care Unit (PNICU) directed by Dr. Murielle Dobrzynski (medical director) and Marie-Christine Nagahapitiyé (head nurse). The unit is working very closely with this training center. Its role is not only to provide the best care to preterm newborns, but also to be the vitrine or "showcase" of NIDCAP philosophy and practices in France. In order to coordinate and implement this developmental approach, a developmental nurse position has been created. Sylvie Bleunven-Minguy, the first French NIDCAP-certified nurse, has been pleased to accept this role. Each year the unit welcomes many delegates from France and abroad.

One goal of the French NIDCAP Center was to work on "changing the system," at a regional and national level. The strategy was to contact and collaborate with national health agencies in order to share our experiences and to suggest NIDCAP as the best approach in caring for preterm newborns. Contacts have been very positive during these past ten years. The Haute Autorité de Santé (French National Authority for Health), whose mission is to improve quality of care in health care organizations, delivered the highest level of certification to the Brest University hospital in 2006, with a special note on NIDCAP stating that it is "a successful and permanent action likely to cause the implementation of similar approaches in other hospitals." In 2006, the Agence Régionale d'Hospitalisation (Regional Hospital Agency, affiliated with the Ministry of Health) included NIDCAP implementation into the 2007-2012 regional plan. In May 2008, the French NIDCAP Center received the Association Nationale pour la Formation Permanente du Personnel Hospitalier (National Agency for Hospital Continuous Education) Award.

As the NIDCAP approach was perceived in the 1990's by French professionals as "too American," efforts were made to build a European network to facilitate contact between groups, to organize meetings and workshops, and to prepare multi-site trials. A grant from the European Science Foundation helped to create this network that consisted of the London, Brussels, Scandinavian, and Netherlands NIDCAP Centers. In December 2008, the third Infant Development in Newborn Intensive Care Meeting (IDNIC) will be conducted in Paris and organized as a joint meeting with the French Neonatal Research Group.

Ten years after the initial decision to implement NIDCAP, the Brest team hosted the Trainers meeting in Combrit, in the South of Brittany (October 2007). All attendees were provided a beautiful, quiet place to reflect and experience the special tastes and sounds of Brittany. Future challenges are to prepare a second NIDCAP trainer and to achieve NFI Nursery Certification. 


\section{The Neuroscience of Skin-to-Skin Contact}

Nils Bergman, MB ChB, MPH, MD

Dor the last fifty years the focus
of newborn care has been on survival, achieved through technological interventions, primarily focused on cardio-respiratory and nutritional support. The underlying assumption has been that the development of the brain was primarily determined by genetic maturation over time, and did not really begin in earnest until some time after birth. The neurodevelopmental needs of premature infants were therefore not considered, while their survival rate was improved. The quality of this survival has, however, not been good, and there is now increasing evidence that the brain requires care! "Developmental Care" is increasingly accepted as a good thing for newborns, premature or not. (While the NIDCAP approach provides very clear definitions about what the implementation of developmental care may mean, most people using this term are vague about what this actually entails). I will in this short article attempt to provide a simple but neuroscientifically based rationale for optimal neurodevelopment, central to which is maternal-infant skinto-skin contact.

Brain development begins much earlier than previously recognized. At 20 weeks post-menstrual age (PMA) all brain structures are in place and functional to some degree. Neurogenesis begins very soon after conception, but surprisingly, is essentially completed at 28 weeks PMA. The 100 billion neurons that have been formed have an inbuilt tendency to be eliminated; in order to survive they need to "fire and wire." The "firing" comes from sensory stimulation, an obvious statement perhaps, but fundamentally important, and long neglected. For any specific pathway there is a salient stimu-

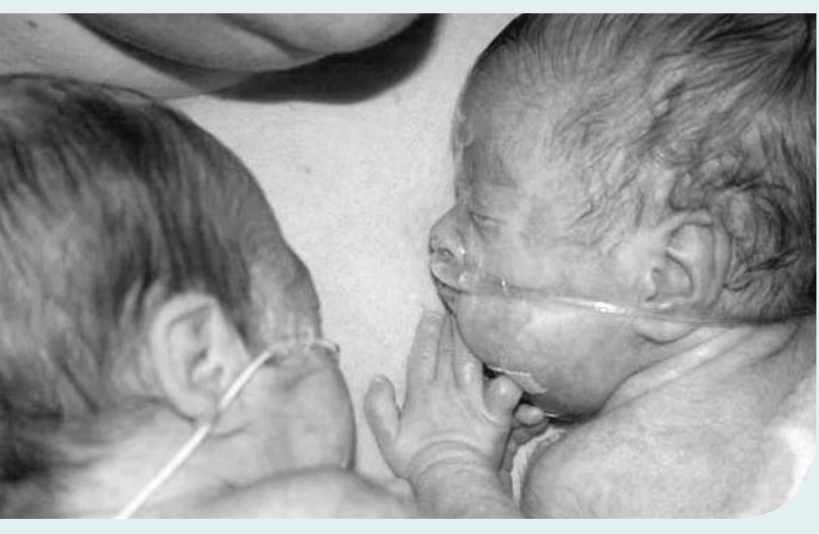

lus, as well as a critical period, or window of expectation. However, brain pathways are integrated circuits, and optimal neurodevelopment requires integrated quality sensory stimulation. ${ }^{2}$ Absence of stimulation during such periods results in failure of the pathway to wire. ${ }^{3}$

In the uterine environment, some fetal sensations are fully operational: sound, smell, and position. However, other fetal sensations are muted, sight in particular. In order to achieve firing and wiring of such pathways, REM sleep periods are responsible for achieving orchestrated "spontaneous synchronous firing" of all sensations. ${ }^{4}$ In past research, blocking such firing in visual pathways resulted in blindness, and resulted in the phrase: "Cells that fire together, wire together, and those that don't, won't." ${ }^{1}$ But the "wiring" part of the brain connections are dependent on REM sleep in other ways also, and on the full sleep cycle. ${ }^{4}$ REM sleep cycles with four stages of non-REM sleep in approximately one hour rhythms, beginning in the last trimester, and is fully evident at term. Brain wiring occurs during this cycle in three distinct phases: acquisition during REM sleep or being awake, consolidation (also called pre-consolidation) during NREM stage 4, and memory formation (also called consolidation) in the early phase of the next REM period. A full sleep cycle is required to achieve connected neuronal pathways. Disruption or deprivation of REM sleep increases neuronal cell death, and reduces final brain mass.

Birth is the most critical event for all mammals. The organism has three major tasks to accomplish ... transition, homeostasis and homeorhesis. In transition the organism must suddenly change its entire cardio-respiratory functionality, while at the same time maintaining its homeostasis (i.e., its internal total metabolic balance). Homeorhesis (Greek for "similar flow") is more demanding than just balance in a stable state; the organism is also developing along a trajectory, which it must maintain. It is the brain's developmental trajectory which is paramount. In the past, the human newborn was regarded as helpless and incompetent. There is in fact astonishing neurological competence wired into the fetal brain in preparation for birth. Neither the competence, nor the conditions for it, have been well understood.

The word "critical period" is not well accepted by the medical profession, but birth is undoubtedly a "critical event." The competence of the mammalian newborn is dependent on its brain circuitry. Brain function is dependent on appropriate sensory stimulations. Throughout evolution, this was provided by the maternal milieu. Every mammal studied attests to "highly conserved perinatal behaviours," 5 in which the newborn plays the primary role in initiation and maintenance, with subsequent elicited responses from mother. It is mother's presence and the stimulations that she provides which are essential for the behaviours which lead to successful transition and subsequent adaptation to extra-uterine life. ${ }^{6}$ That adaptation will 
immediately require the continued provision of "basic biological needs" of warmth, nutrition and protection. It may be useful to distinguish that these are needs for the body, as opposed to the brain which needs stimulation. Maternal-infant togetherness ensures provision of warmth, nutrition and of protection. The critical behaviour that brings these together is breastfeeding. Breastfeeding is at the same time an umbrella providing every sensory modality to the brain's developing pathways. ${ }^{7}$ Thus the mother's presence provides both basic biological and neurological requirements.

Primates deliver young which are biologically immature, and maternal-infant skin-to-skin contact is the rule, not least due to thermal requirements. Skin-toskin contact stimulates neural pathways that reach the amygdala directly (along with smell), without passing through higher brain centres. ${ }^{8}$ These may be seen as primary regulating sensations, decribed under the "continuity hypothesis." The amygdala is described by le Doux as being at the core of the "emotional brain." 10 From the amygdala autonomic regulation of all body systems is achieved (downward function), and approximately 200 randomized controlled trials on skin-toskin contact on premature human infants attest to this regulation. From the amygdala, key pathways fire and wire to higher brain centers (upward). One of these is the amygdala prefrontoorbital cortical pathway, ${ }^{8}$ which links the emotional core of the brain to the "behavioural activation system" of the brain, ${ }^{11}$ which determines future "approach versus avoid" tendency. This pathway is specifically "fired" by skin-to-skin contact that can later be measured in right frontal EEG assymmetry, a measure of physiological and psychological resilience. ${ }^{12,13}$ This skin-to-skin contact may be at the core of subsequent attachment behaviour and also has profound effects on regulating the sleep cycle, ensuring adequate deep sleep for NREM4 and spaced periods of REM. ${ }^{14}$ Thus the effect of maternal-infant skin-to-skin contact is one of "dual coding," 15 achieving simultaneous physiological regulation and emotional (or psychological) attachment. It may be the basic building block of future capacity to achieve "stability through change," Schore's definition of health. ${ }^{8}$

Maternal-infant separation significantly disrupts the processes described above. Sleep cycling is absent during incubator care. But, since separation is accepted as "normal," the physiological state it produces is regarded as normal. In fact, the response of the amygdala is to ensure a survival state, homeostasis without homeorhesis. Schore describes this in adults as "hyperarousal dissociation." ${ }^{3}$ In early primate research, this was called "protest despair" in separated infants. ${ }^{16}$ That this applies to the human newborn needs to be stated, even if obvious.

Neuro-cognitive development (as in Bayley, ${ }^{17}$ or IQ) has been the basis for measuring the long term impact of modern newborn care, specifically in premature infants. I would suggest on the basis of this neuroscience that these are invalid measures. The processes that are

References:

1. Shatz CJ. The developing brain. Sci Am 1992 September;267(3):60-7.

2. McCain HN, Mustard JF. Neuroscience and early child development. In: Reversing the real brain drain: Early Years Study. 25-52. 1999. Toronto, ON, Canada, Ontario Children's Secretariat. Ref Type: Generic.

3. Schore AN. The effects of early relational trauma on right brain development, affect regulation, and infant mental health. Infant Mental Health Journal. 2001; 22 (1-2): 201-69.

4. Graven S. Sleep and Brain Development. Clinics in Perinatology. 2006; 33: 693-706.

5. Keverne EB, Kendrick KM. Maternal behaviour in sheep and its neuroendocrine regulation. Acta Paediatr Suppl. 1994 June; 397: 47-56.

6. Alberts JR. Learning as adaptation of the infant. Acta Paediatrica (Oslo, Norway: 1992). 1994; Suppl 397: 77-85.

7. Gallagher W. Motherless Child. The Sciences. July/August, 12-15. 1992. Ref Type: Generic.

8. Schore AN. Effects of a secure attachment relationship on right brain development, affect regulation, and infant mental health. Infant Mental Health Journal. 2001; 22 (1-2): 7-66.

9. Anderson GC. Touch and the kangaroo care method. In: Field T, editor. Touch in Early Development.Hillsdale: L Earlbaum; 1995. p. 34-51.

10. Le Doux J. The Emotional Brain: The mysterious underpinnings of emotional life. New York: Simon \& Schuster Paperbacks; 1996. disrupted are regulation and attachment, and the latter leads primarily to emotional and social development, not cognitive. Emotional and social intelligence would be valid measures of developmental care. ${ }^{15}$

Social and emotional intelligences do in fact provide a platform for higher cognitive functions, and cognitive functions almost certainly are improved, albeit indirectly. But "IQ" is a complex and diffuse concept, and may be seen as a remote downstream effect. There is no direct cause-effect between these intelligences and cognitive capacity. High IQ may even be a compensatory mechanism in some emotionally deprived individuals. From an evolutionary perspective, the primary objective of the primate perinatal period was to achive emotional and social competence.

Optimal neurodevelopment requires that our care and technology is applied (and adapted as necessary) so as to ensure there is no separation of the mother-infant dyad. Maternal-infant separation is, unfortunately, the norm in our health system. Maternal-infant skin-to-skin contact, not separation, is the norm of our biology.

11. Amodio DM, Master SL, Yee CM, Taylor SE. Neurocognitive components of the behavioral inhibition and activation systems: Implications fdor theories of self-regulation. Psychophysiology. 2008; 45: 1-11.

12. Diego MA, Field T, Jones NA, Hernandez-Reif M. Withdrawn and intrusive maternal interaction style and infant frontal EEG asymmetry shifts in infants of depressed and non-depressed mothers. Infant Behavior \& Development. 2006; 29 (2): 220-9.

13. Jones NA, McFall BA, Diego MA. Patterns of brain electrical activity in infants of depressed mothers who breastfeed and bottle feed: the mediating role of infant temperament. Biological Psychology. 2004; 67(1/2): 103-24.

14. Ludington-Hoe SM, Johnson MW, Morgan K, Lewis T, Gutman J, Wilson PD et al. Neurophysiologic Assessment of Neonatal Sleep Organization: Preliminary Results of a Randomized, Controlled Trial of Skin Contact With Preterm Infants. Journal of the American Academy of Child \& Adolescent Psychiatry. 2006; 45 (12): 1455.

15. Greenspan SI, Shanker SG, Phil D. The First Idea. Da Capo Press; 2006.

16. Harlow HF, Suomi SJ. Social Recovery by Isolation-Reared Monkeys. Proceedings of the National Academy of Sciences. 1971; 68 (7): 1534-8.

17. Bayley N. Bayley Scales of Infant Development-II, The Psychological Corporation. 2001. 


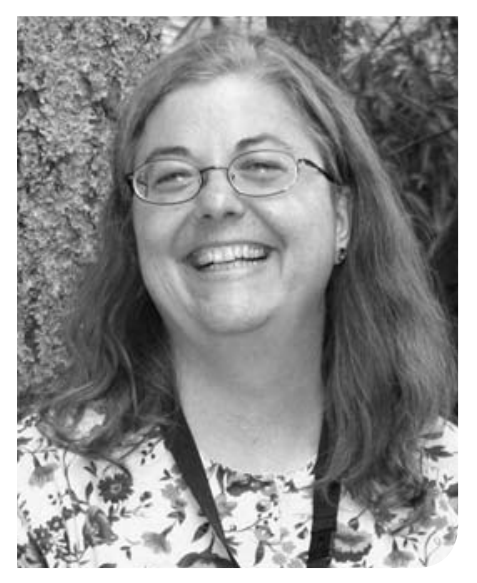

\title{
Kangaroo Mother Care
}

\author{
I don't remember when I first heard about "kangaroo care." I had worked in \\ the intensive care nursery since 1988, but my first encounter with the term \\ "kangaroo care" was in the articles that I read during my graduate nursing \\ program in 1992. What struck me was not only how simple the concept was, \\ but also how it was discovered.
}

$\mathrm{K}$ angaroo care developed out of necessity in a country where the ability to care for all the premature infants in the hospital was hampered by lack of equipment. It was a measure that, although carefully and thoughtfully accomplished based on what is "natural," was nevertheless born from a desperate need, not a result of controlled research. Since then research with kangaroo care has looked at a variety of aspects, from documenting the safety for high risk infants engaged in kangaroo care, to examining the emotional benefits to mothers who participate, to identifying the physiological processes and mechanisms of kangaroo care that appear to facilitate development of the infant. ${ }^{1,2}$ There is still much to research and to understand. In the NICU, we also encourage fathers to participate and recognize how beneficial this kind of holding is to fathers and their infants. However, the initial concept, perhaps more accurately called "kangaroo mother care," where the mother is the source of continuous warmth and nourishment to the infant, is the subject of this reflection.

Many people object to the term "kangaroo care," saying that it denigrates the unique humanness of the infant/parent relationship. That it makes light of, or makes too "cute" an activity that has profound emotional and physical consequences for both parties. Perhaps because I am married to an evolutionary ecologist, I see this reference to our mammalian heritage as natural, not offensive. To me, the term also reflects an accurate perspective of this activity. Anthropologists and biologists recognize the developmental phases that mammalian species move through in their transition from infant to adulthood, which can be divided into: the uterine phase, the breast phase and the social/community phase. ${ }^{3-5}$ Human infants are an unusually dependent mammalian species, born before they are well developed. This is thought to be an evolutionary compromise because a more mature brain would not be able to be delivered in the woman whose pelvis has adjusted to bi-pedalism. So the infant is born while still immature and must spend significant time with the mother staying warm and being provided nutrition while they complete the developmental phases that in other more precocial species are accomplished in utero. Like marsupials, who very competently find their way to their mother's teat, and bask in the warmth of her pouch, so the human infant is very competent to continue physical, cognitive and social development while being supported by the mother during extensive bodily contact.

This extensive "breast phase" is still experienced in many non-technological communities, but there has been a cultural shift in industrial societies where the "breast phase" is shortened or non-existent. While physical survival is possible without the mother's milk and warmth, there can be severe emotional and social consequences, some of which we are just beginning to recognize. ${ }^{6}$ Technology in the NICU has increasingly become more sophisticated in supporting the physical well being of premature infants. Can we now begin to acknowledge that these vulnerable infants are the ones that need the most contact with their mother? Kangaroo mother care, where the mother serves as the source of warmth and nutrition in a hospital setting, has been successful in promoting positive outcomes of low birthweight infants in a number of countries where options are limited, although larger, randomized studies are still needed to document these effects. ${ }^{7,8}$

Perhaps part of our dilemma in the United States is our inability to see mother and child as an inseparable dyad, in our failure to acknowledge this "breast" phase of development. Our workplace culture has long been a source of frustration for those

$10 \cdot 2008 \cdot$ Developmental Observer 
women who wish to ensure their employment, yet still meet the needs of their small, nursing infants. Frequently, this dichotomy occurs much earlier. For the healthy, newly delivered infant, the mother and infant stay together and never need to be separated. If the mother goes home from the hospital, and the baby must stay behind, our expectations change. Healthcare systems do not acknowledge the unhealthiness of the separation, and often it is the most at risk families that cannot manage to overcome it. We have evidence that kangaroo care will improve the development of the premature infant and may improve the parent/infant relationship, and that separation of mother and child may be damaging. ${ }^{1,2,9,10,11}$ So why is there so little support for parents to be continuously available to their hospitalized infants? A neighboring hospital has a very aggressive breastfeeding policy that makes it a practice of informing the mothers of premature infants that they have no choice but to provide milk for their infants, because it is clearly the best nutritional option. Should we make kangaroo care mandatory for premature infants who are in the process of forming the foundation of their emotional and cognitive lives?

I am cast back to when my daughter, Miriam, was born seven weeks prematurely many years ago. I was admitted for severe epigastric pain and very suddenly needed an emergency C-section. I became an educational object for the obstetric residents, as they were brought by in groups and lectured on the relatively newly named "HELLP" syndrome that I had. Miriam came into the world a few minutes shy of Christmas Eve, crying strongly as she was handed to the pediatrician, her arms and legs waving frantically in the air. As she was weighed and examined, her crying subsided into a rhythmic grunting, which meant that she was destined for the special care nursery. My arms were strapped down to the operating room table, and just before Miriam was transferred out, she was brought close to my face, where I could only awkwardly nuzzle her head with my nose and cheek.

Miriam was in the special care nursery for only a few hours. I, however, stayed in labor and delivery for a day and a half, heavily sedated with magnesium; my arms oozing blood from the frequent blood draws to monitor my falling blood counts. It is only in hindsight that I realize how traumatizing this experience was, and how battered and bruised I felt, both emotionally and physically. My pregnancy had been disrupted, and I had become truly "sick" and afraid of my body. The first time I felt at peace was when Miriam was brought to me as she was being transferred from the special care to the normal newborn nursery. She was placed on my chest, and though my magnesium intoxicated brain wasn't processing all that the nurse was telling me, what came through was the warmth of her skin, the feel of her breath as her body rose and fell, and her little squeaks, squeals and squirms as she settled down on me. The NICU nurse in me was trying hard to think of the questions I should be asking, but my sedated nervous system could not formulate them. However, the mother in me was reassured, feeling through my skin and the core of my being that my baby was okay.

Since then, I realize how much that primal reassurance meant to me, and I believe that babies too need that comfort from closeness with their mother. This contact is the closest the premature infant can get to regain the "uterine phase" while transitioning to the "breast phase." This is what is expected, and what is needed. As NICU professionals, we need to explore ways to make it an expectation of care for all premature infants.

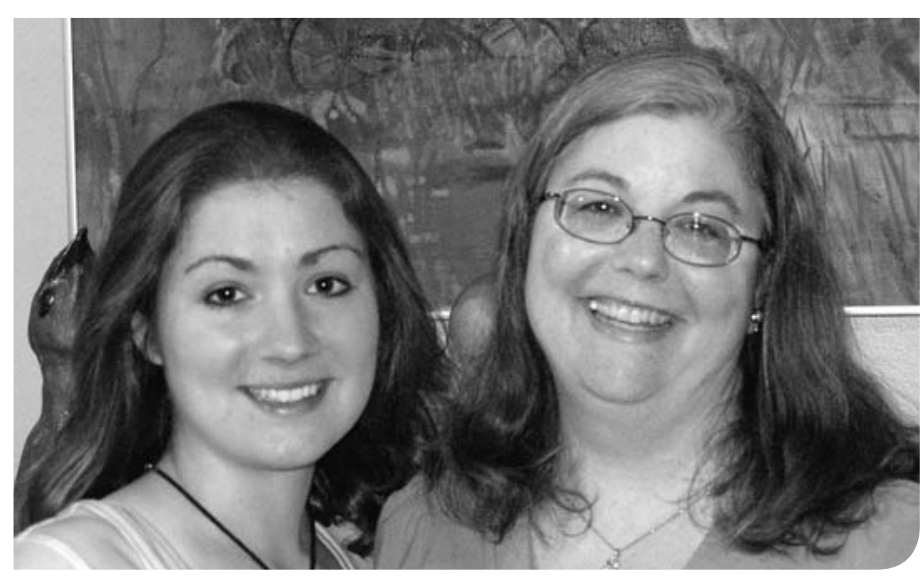

References:

1. Dodd VL. Implications of Kangaroo Care for growth and development in preterm infants. Journal of obstetric, gynecologic and neonatal nursing 2005; 34 (2): 218-232.

2. Browne, JV. Early relationship environments: physiology of skin-to-skin contact for parents and their preterm infants. Clinics in Perinatology 2004; 31: 287-298.

3. Hofer MA. Early social relationships: A psychobiologist's view. Child Development 1987; 58: 633-647.

4. McKenna J, Ball H, Gettler L. Mother-infant cosleeping, breastfeeding and sudden infant death syndrome: what biological anthropology has discovered about normal infant sleep and pediatric sleep medicine. - American Journal of Physical Anthropology 2007; 134(S45): 133-61.

5. Als H, Gilkerson L. The role of relationship-based developmentally supportive newborn intensive care in strengthening outcome of preterm infants. Seminars in Perinatology 1997; 21 (3) $178-189$.

6. Schore AN. Attachment and the regulation of the right brain. Attachment and Human Development 2000; 2 (1): 23-47.

7. Cattaneo A, Davanzo R, Bergman N, Charpak N. Kangaroo mother care in low income countries. International Network in Kangaroo Mother Care. Journal of Tropical Pediatrics 1998; 44: 279-295.

8. Conde-Agudelo A, Daiz-Rosello JL, Belizan JM. Kangaroo mother care to reduce morbidity and mortality in low birthweight infants. Cochrane Database of Systematic Reviews 2008.

9. Tessier R, Cristo M, Velez S, Giron M, Ruiz-Palaez JG, Charpak Y, Charpak N. Kangaroo Mother Care and the Bonding Hypothesis. Pediatrics 1998; 102: el7.

10. Hofer MA. Hidden Regulators in attachment, separation and loss. Monographs of the Society for Research in Child Development 1994; 59: 192-207.

11. Feldman R, Eidelman AI, Sirota L, Weller A. Comparison of skin-to-skin (kangaroo) and traditional care: parenting outcomes and preterm infant development. Pediatrics 2002; 110 : 16-26. 


\section{Vicky Youcha, EdD, and Tracy Price-Johnson, MA}

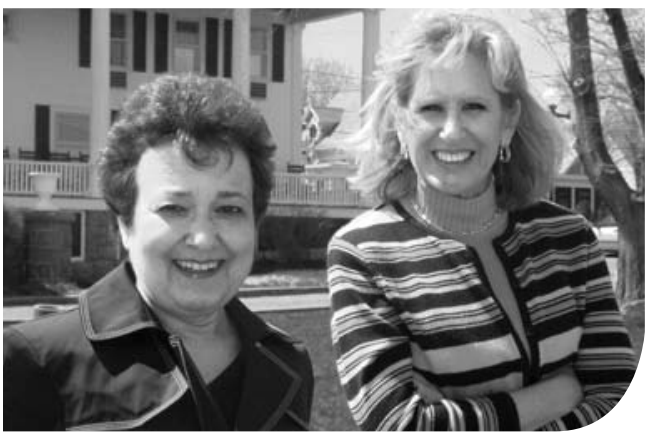

Who can better advise professionals in the NICU than people who have experienced the ups and downs of the NICU roller coaster ride? The NIDCAP Federation International (NFI) recognizes the unique contributions that experienced parents can provide and has recently added two new family members, Vicky Youcha and Tracy Price-Johnson, to the Board of Directors.

$\mathrm{T}$ here could be no better spokespeople for parents than these two unique and especially talented people. Both Vicky and Tracy have had up close and personal experiences with their children and grandchildren in NICUs. They are each national leaders in the field of early intervention and have made their mark on education and advocacy and sensitive caregiving for infants and children who interface with the health care system. Their voices and contributions on the NFI board will be critical to the future directions that the NFI pursues.

Vicky Youcha is currently leading a multimedia project focused on preventing, treating, and living with traumatic brain injury, for a public broadcasting station in the Washington D.C. area. She compares her present efforts with the technical world of the NICU where life and death decisions may be made in an instant often engulfed by emotions.

Vicky is an experienced "two timer" in the NICU. Her daughter and grandson both began their lives in an NICU. Despite her role as Developmental Specialist and vast knowledge of parent-infant development and its importance, the NICU was a difficult place to navigate. She continually uses her own past experiences to support and strengthen her daughter's relationship with her grandson by encouraging techniques such as kangaroo care holding. She expresses with passion how the connections developed during that critical period in the intensive care nursery have strengthened attachment between her daughter, son-in-law and her grandson. Vicky recognizes the need to continuously support "parents to be parents" while their infants are in the NICU and articulates her perceptions of how parenting can have a direct impact on improving the outcomes of infants born prematurely.

Vicky's first encounter with NIDCAP came when Dr. Heidelise Als presented at George Washington University (GWU) in the early 1980's about the infant's experience and the impact the sensory environment had on the developing baby. These presentations validated her own thoughts as she parented her daughter in the NICU. This encounter strengthened her resolve to support families in developing strong relationships with their infants and to develop systems to support families to be an integral part of the health care team.

As a professional, Vicky has had extensive knowledge and experience with early childhood development and special education. She has had a long history as a Developmental Specialist, as well as directing an early intervention program at GWU. She received many national grants focused on including children with special needs in regular early childhood settings. Vicky has published numerous articles on national policy recommendations and guidelines for Individualized Family Service Plans and Implementation Resources along with the Training Manual for Head Start Regulations for Children with Disabilities. In her work at Zero To Three, Vicky directed several projects. One was aimed at helping juvenile and family court judges improve outcomes for infants and toddlers. Another was shepherding the Leaders for the $21^{\text {st }}$ Century program for Zero to Three Fellows, where she encouraged and exemplified leadership in the infant and toddler field.

Vicky is known to take adventure trips to remote areas to kayak and ski. She is a tiny but powerful force to be reckoned with, and is known to take on Mother Nature by storm, and with a smile. She also cuts a mean rug with swing dancing. But her passion is babies - not only her grandson, but also all babies who come to the world with special needs. Her passion and treasure chest of knowledge about infants and their families spill out with each story she shares.

Tracy Price-Johnson is an accomplished public speaker, educator and advocate for families. Her daughter Hayley was born and cared for in a NICU for her first three and a half months after her birth and developed significant disabilities. As Hayley grew older, Tracy used all her professional and newly found parenting skills to increase public awareness and advocacy in support of family centered care principles for infants and children in the health and education systems. Tracy continues to teach at the University of Colorado, Denver School of Medicine, JFK Partners University 


\section{Attachment Theory: A Natural Fit with NIDCAP Practice}

\begin{abstract}
4 key goal in the work of all NIDCAP professionals is sup-

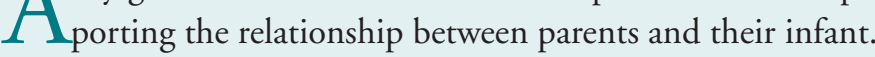
The synactive theory ${ }^{1}$ provides a powerful theoretical basis for understanding the infant in the context of the unexpected environment of the NICU. Many NIDCAP practitioners have found attachment theory to be another valuable resource. Like the synactive theory, it combines rich and complex theory with a large body of empirical support. ${ }^{2}$

These two theories also have in common their deeply humanistic worldview and a commitment to relationships as a core value in all clinical work. They are mutually supportive in guiding work with parents in the NICU, and in focusing on parental relationships with their infants as well as with their infants' caregivers. In addition, these theories share a firm grounding in ethology and evolutionary biology ${ }^{1,3}$ and a profound respect for the importance of patient, naturalistic observation of infants in guiding theory and practice. ${ }^{4,6}$ They also offer a framework for understanding how the physical and interpersonal environment influences the immature developing human brain, shaping its structure and function, and thus help to determine the individual's future. ${ }^{7,8}$

An understanding of attachment theory can support the clinical goals of NIDCAP developmental practitioners and guide interactions in the NICU in a number of ways. First, it is important to note that attachment relationships include those between parents and caregivers as well as those between children and parents. Bowlby ${ }^{3}$ and subsequent researchers are clear that attachment behaviors, involving the seeking of proximity to figures seen as stronger and able to help in stressful situations, continue throughout life. As parents strive to cope successfully with the overwhelming emotional and physical challenges of having an infant in the NICU, staff who are knowledgeable and powerful in this environment may be seen as attachment figures able to provide comfort and safety to parents. Parents who receive this kind of support may then be able to rally their own strengths on behalf of their infants. Staff who understand this role, and are comfortable with meeting the attachment needs of new parents dealing with the crisis of preterm birth, have a powerful opportunity to facilitate the parents' ability to develop the strong attachment relationships with their infant that will help ensure their optimal outcome. This may be seen clinically in situations where parents are perceived as being needy, lacking trust in staff, or appearing fearful in handling their infant.

In their role of supporting the developing parent-infant relationship it is extremely important that staff: 1) are aware of their own feelings toward the infant, and strive to facilitate the relationship between the parent and the infant, rather than allowing their own empathetic connection to the infant supplant the parents' primary relationship to their child; and 2) seek reflective guidance from a psychiatrist, psychologist, or a consultant with a clinical mental health background, an essential support as the

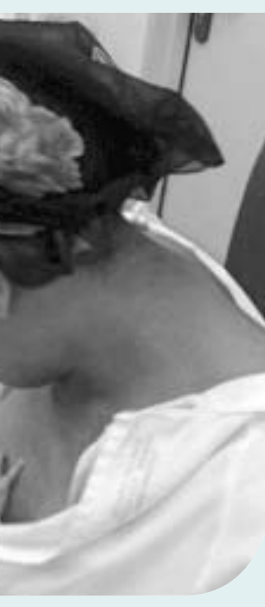
staff strive to accomplish these goals. With the reflective guidance and support of a clinical mental health professional, nurses or other staff may begin to assess and address the underlying concerns haunting the parent, as well as the nature of the parent's past and present attachment relationships. This may provide the kind of support that meets the parent's appropriate needs for attachment figures in this emergency. In practice, this appears as: verbal and non-verbal acceptance of needs; offering the time and interest to share and process the level of disclosure comfortable for the parent; joining with the parents in their efforts to understand their infant's needs (e.g., close observation of the infant's behavioral signals); supporting the parents in their role of providing care to their infant (e.g., skin-to-skin holding, breastfeeding); and facilitating their active participation in the decision-making process. This effort flows naturally into support of the parent-child relationship. The parent's drive to establish and maintain physical and emotional closeness with the infant, and the infant's increasingly competent efforts to orient toward the parent's voice, body and face, are facilitated when the parent feels secure and connected themselves.

When parents worry aloud, as some do, whether they are "bonded" with their infants, attachment concepts suggest several helpful responses. For example, one can honestly assure parents that the very fact that they are asking that question is an indicator of developing attachment. Some parents may think and worry about their infant when they are not in the nursery, or they may think that it "doesn't feel right" to leave their infant behind when they go home. Many parents may experience these feelings, which again are indicators of parental attachment with the infant, predicting future blossoming of infant attachment to the parent.

Specific practices and examples discussed above, however, are less important than integrating an understanding of the principles of attachment into the world view and underlying 


\section{Breastfeeding \& Development}

T here is growing evidence that breastfeeding enhances neurodevelopment. Claims of benefits for breastfeeding have often been disputed on the grounds that mothers from more privileged socioeconomic backgrounds are more likely to breastfeed, thus skewing the outcomes. A cluster randomization trial ${ }^{1}$ involving 31 Belarussian maternity hospitals, enrolled 17,046 healthy breastfeeding infants, and included an intervention group that received breastfeeding promotion modeled on the Baby Friendly Initiative. ${ }^{2}$ Breastfeeding uptake was significantly higher in the intervention group compared to the group where mothers were left to follow their own inclination, as were scores on the Wechsler Abbreviated Scales of Intelligence ${ }^{3}$ at six and one-half years of age. Teachers also evaluated academic achievements more highly in the intervention group. The randomization and sheer size of this study strengthen arguments in support of an independent effect of breastfeeding on development. Whether or not this is due to the ingestion of breastmilk or increased closeness between mother and infant would be difficult to demonstrate.

Much of the evidence for enhanced neurodevelopment relates to term infants but Vohr et al. ${ }^{4}$ followed up 1035 extremely low birth weight infants on 15 sites to 18 months corrected age and with multivariate analysis, adjusting for confounders such as socioeconomic status, confirmed a significant independent association of breastmilk on the Bayley Scales of Infant Development-II ${ }^{5}$ (i.e., Mental, Psychomotor and Behavior Rating Scales). The more breastmilk the infants ingested the stronger the association. Feldman and Eidelman ${ }^{6}$ found a direct association between breastmilk and neurobehavioral organization in preterm infants and postulated that there may be a link between maternal depression, lower quantities of breastmilk and poorer developmental outcomes.

The health benefits of breastmilk for preterm infants are well established and include protection from necrotizing enterocolitis (NEC), ${ }^{7}$ which may require intensive care treatment and surgery, thus exposing the infant to the developmental risks associated with severe illness, restricted nutrition and possibly the iatrogenic effects of intensive care. Avoiding NEC is therefore likely to reduce the risk of negative developmental outcomes. Breastfeeding has well known health benefits for mothers too.

While breastfeeding rates for preterm infants admitted to newborn intensive care units are often assumed to be low in comparison to those for the healthy term newborns, this may be deceiving. A study of the Pregnancy Risk Assessment and Monitoring System (PRAMS) ${ }^{8}$ in 27 US states over four years found that when the data was adjusted for multiple confounders, such as maternal race, age, education and antenatal care; NICU admission actually appeared to have a beneficial effect on breastfeeding. ${ }^{9}$ Anecdotal reports from NIDCAP Training Centers suggest that a higher proportion of infants may be discharged breastfeeding from the newborn intensive care unit, than from the maternity unit in the same hospital. Warren et al. ${ }^{10}$ found that when breastfeeding support was combined with developmental care, breastfeeding increased considerably; at discharge $83 \%$ were breastmilk fed although $8 \%$ were taking breastmilk from bottle or cup; at that time the maternity unit was achieving similar rates to the national average of $65 \%$.

Bottle feeding may be offered on the assumption that it will accelerate discharge. Profit et al. ${ }^{11}$ reports a mean age on discharge from the newborn intensive care unit of 36.3 weeks corrected age for infants born between 30 and 35 weeks gestation in the United Kingdom (1998-99) and 35.9 weeks in California (2001-2003). Nyqvist ${ }^{12}$ described breastfeeding development in a diverse but small $(\mathrm{n}=15)$ number of much younger babies (born between 26 and 31 weeks of gestational age) in a Swedish nursery that provided skilled breastfeeding support, facilities for rooming in and an individualized developmental care approach. She reports a median age of 35.4 weeks corrected age at discharge from hospital to home. Warren et al. ${ }^{10}$ in a retrospective study collected data on all infants born in one year before 35 weeks gestational age $(n=60$; range $24-34$ gestational age), regardless of complications, in a nursery that favored an individualized developmental care approach. Fully breastfed and other breastmilk fed babies were discharged at a median age of 36 weeks. These two studies suggest that the potential for lactation support combined with developmental care to facilitate early discharge from hospital for very preterm infants is worth further investigation.

Newborn intensive care units often offer bottles before the breast and may suggest that this should begin at around 33-34 weeks when maturation of oral motor skills makes suck feeding relatively safe. Nyqvist ${ }^{12}$ suggests that breastfeeding can be presented to the infant much earlier, provided appropriate support is offered. She describes breastfeeding behavior in infants born between 26-31 weeks of gestational age, and reports that infants as young as 29 weeks were rooting and that by $31-32$ weeks corrected gestational age some of these infants were competently latching on, with long sucking bursts and repeated swallowing.

A common misconception holding back breastfeeding is the idea that women will feel pressurized and stressed by this expectation. Sisk et al. ${ }^{13}$ found that lactation counseling given to mothers of very low birth weight babies increased lactation initiation and breastfeeding without increasing maternal stress and anxiety. Kavanagh et al..$^{14}$ used semi-structured interviews with mothers of preterm infants to explore their perceptions of breastfeeding. These mothers described specific emotional advantages that they related to breastfeeding, indicating that the rewards were worth the effort.

Clearly, the research cited within this article demonstrates the importance of breastfeeding support within a developmental care program because it may enhance developmental outcomes, promote early discharge, and be an advantage for mothers as well as their infants.

References on page 18

$14 \cdot 2008 \cdot$ Developmental Observer 
This column provides our readers with current information regarding developmental resources related to NIDCAP.

\section{Articles}

1. Als H \& Butler S. Newborn individualized developmental care and assessment program (NIDCAP): Changing the future for infants and families in intensive and special care nurseries. Early Childhood Services. 2008; 2 (1): 1-19.

2. Lawhon g \& Hedlund RE. Newborn individualized developmental care and assessment program (NIDCAP) training and education. Journal of Perinatal and Neonatal Nursing. 2008; 22 (2): 133-144.

3. Smith KM, Butler S \& Als H. Newborn individualized developmental care and assessment program (NIDCAP): Changing the future for infants and families in intensive and special care nurseries. Italian Journal of Pediatrics. 2007.

\section{Book Chapters}

Als H, \& Butler S. Screening of newborn and maternal wellbeing. In: Haith $M \&$ Benson J (eds). Encyclopedia of Infant and Early Childhood Development. Amsterdam: Elsevier. 2008; 3: 66-78.

\section{Books}

1. Disorders of Behavioral and Emotional Regulation in the First Years of Life, Early Risks and Intervention in the Developing Parent-Infant Relationship.

Mechtild Papousek, Michael Schieche, and Harald Wurmser, Editors. Translated by Kenneth Kronenberg. 2007. Zero To Three.

Recently translated, this book provides an in depth overview of emotional regulation from birth to three years of age. A thorough review of excessive crying, sleep disorders, feeding disorders and behavioral difficulties is provided.
Evaluation of behaviors and therapeutic approaches are discussed in detailed case studies. 346 pages. $\$ 49.95$.

\section{Early Development and the Brain: Teach-} ing Resources for Educators.

Linda Gilkerson and Rebecca Klein, Editors. 2008. Zero To Three.

This is a nine-unit curriculum that translates scientific research into practical suggestions to help early childhood professionals understand the link between caregiving and brain development. Topics include brain structure and function, language, and the effects of stress and maternal drug use on brain development. CD-ROM includes PowerPointTM slides and course handouts. 794 pages. \$359.99.

\section{Conferences}

1. Developmental Interventions in Neonatal Care Conference: October 1-4, 2008, Denver, Colorado, USA. Sponsored by Contemporary Forums. The Preconference (October 1) offers presentations on individualized developmental care designed to highlight developmental intervention practices. Topics include Essential Concepts In Developmental Care, Management of Infant Behaviors, Development of Feeding Skills in Preterm and Term Infants, and the Role of Movement and Posture in Promoting Physiology. The Main Conference (October 2-4) offers plenaries and concurrent sessions covering current research updates, practical strategies for providing effective developmental care and applicable medical information. For more information, please visit the conference website at: www.contemporaryforums.com.

\section{Infant Development in Neonatal} Intensive Care (IDNIC): "Closing the gap between research and practices." December 12-13, 2008, Paris, France. Although the quantity of research on positive impact of non-pharmacological strategies on outcome in preterm neonates has expanded, the gap between research and practice remains wide (pain control, early intervention, breast milk). The goals of this conference are to explore reasons for this gap and to offer strategies for bridging it. Please visit the conference website at: $w w w$. info-congres.com.

3. The $22^{\text {nd }}$ Annual Gravens Conference on the Physical and Developmental Environment of the High Risk Infant: January 21-24, 2009, Clearwater Beach, Florida, USA. This conference focuses on developmental care and the impact of the physical environment on premature and high-risk babies. This year's focus is on the psychological and physiological interactions in the NICU. The March of Dimes Family Support Summit, which will address current application of family support services in NICUs, will be held in conjunction with the Gravens meeting. For more information, please visit the conference website at: www.cme.hsc.usf.edu/hri09.

4. The $4^{\text {th }}$ International Conference on Brain Monitoring and Neuroprotection in the Newborn: February 20-22, 2009, Orlando, Florida, USA. This conference focuses on new strategies and technology in the assessment of early brain function. It is intended to bring the most current research and application in clinical practice to a forum where the results can be translated for use by clinicians. For more information, please visit the conference website at: www.cme.hsc.usf.edu/brain09.

5. The Fragile Infant Feeding Institute (FIFI): Spring of 2009 (specific date and site to be determined). This conference focuses on the development of feeding in preterm and high-risk infants. Using the NIDCAP model, this four and a half-day conference teaches evidence based interventions using individualized assessment and supportive strategies applied to clinical practice for in-hospital and community professionals. To have your name placed on a distribution list for first come-first served selection, please contact Joy Browne, $\mathrm{PhD}$ at: browne.joy@tchden.org. 
6. Multidisciplinary Family Centered Care Conference: The Fourth International Conference on Patient and Family Centered Care: August 17-19, 2009, Marriott Hotel Downtown, Philadelphia, Pennsylvania, USA. This conference is sponsored by the Institute for Family Centered Care and will address innovative programs dedicated to promoting partnerships between patients, family and health care professionals and health care systems. For more information, please visit the conference website at: $w w w$. lstreeter@iffcc.org.

\section{Recognition of Developmental Care Competency}

National Association Neonatal

Nurses Advanced Competency in

Developmental Care

The purpose of this Program is to promote excellence in professionalism by acknowledging the healthcare providers who have acquired a body of knowledge and expertise in the field of providing developmental care. Please see: $w w w$. nann.org/-8acdc.html.

We invite you to send in information that you may encounter, such as upcoming conferences, websites, books, journals, articles, videos, etc., that may be shared with our readers. Please send items for inclusion in the Developmental Observer to Diane Ballweg at: developmentalobserver@nidcap.org.

\section{The Newborn Individualized Developmental Care and Assessment Program (NIDCAP)}

The Newborn Individualized Developmental Care and Assessment Program (NIDCAP), originated in 1984 by Heidelise Als, PhD, is a developmental, family centered, and evidence-based care approach. NIDCAP focuses on adapting the newborn intensive care nursery, including all care and treatment and the physical environment, to the unique neurodevelopmental strengths and goals of each high risk newborn and his or her family, the infant's most important nurturers and supporters. For a complete description of training centers and the training process please visit our website: www.nidcap.com.

\section{The Assessment of Preterm Infants' Behavior (APIB)}

The Assessment of Preterm Infants' Behavior (APIB) is a comprehensive and systematic neurobehavioral assessment of preterm and fullterm newborns developed by Heidelise Als, PhD and her colleagues (published in 1982, see www.nidcap.com for details). The APIB requires in-depth training and provides a highly valuable resource in support of developmental care provision by professionals and families. 
Dear Editors,

I have completed my thorough reading of the recent $D O$ and wanted to tell you all how wonderful I thought it was. The Advanced Practicum piece is excellent and will guide all of us.

I am sure that very soon we will be wondering how we lived without it. I was impressed with what a clear overview of many aspects of individualized developmental care and NIDCAP that is presented. The personalities, the essence of who and what we are really comes through. As usual, I am very proud to share it with potential funders and colleagues. Thank you all for all of your hard work--it is quite amazing.

And gretchen and Rodd, congratulations on your recent publication in The Journal of Perinatal and Neonatal Nursing on NIDCAP. This is an excellent piece for nurses and NICU staff as well as managers and organizers. I have sent it all around the University of California at San Francisco. Its publication is very helpful for the work we are trying to generate here. Thank you for helping us elucidate and articulate the core of what we do.

Sincerely,

Kathleen VandenBerg, PhD

Dear Editors,

Presently as a NIDCAP Trainee as well as the physical therapist dedicated to the NICU and also the chairperson of the NICU Development Council, I am embarking on the NIDCAP Advanced Practicum towards certification. Having completed ten systematic NIDCAP observations of premature infants during a care or procedure has prepared me to progress to the next phase. In light of beginning the process of the advanced practicum (AP), I felt compelled to share my reflections of the process thus far.
For me the road to become NIDCAP certified began one year ago. gretchen Lawhon came to St. Luke's Hospital in Bethlehem/Allentown, Pennsylvania to provide the initial knowledge, guidance, and instruction on how to perform the NIDCAP observations of premature infants. Filled with excited anticipation I began to observe changes in infants that I had never observed. From this initial experience, I learned to develop a better understanding of premature infants' methods of communication noticing physiologic and behavioral changes of infants before, during and after their care. From this point on my role became that of the translator of the infants' needs and dislikes for their caregivers.

Taking the time to exclusively observe an infant without performing an intervention is a valuable opportunity to fully embrace the infant's stressors and likes. Heightening my attentiveness to infants' reactions taught me to stop what I am doing when I see small signs of stress. This gives the infant a chance to recover and manage his/her care to minimize stressful procedures. Despite over thirty years of working with infants of various ages in center-based programs and in the infants' homes, I found that there is a tremendous amount to learn and to marvel at when discussing infant growth and developmental achievements.

I look forward to developing a special relationship with the infant and family during my AP experience by meeting with them weekly or biweekly. With this practicum I look forward to being able to share my findings with the parents and caregivers. During that time I will have a chance to integrate what I have learned and be creative with the communication baby booklet.

Despite working with infants for many years in their homes with Early
Intervention, this will be my first experience going from up to 72 hours post birth to the home visit. I look forward to implementing individualized care and hopefully alluring the staff to embrace this concept. Providing suggestions for the family and staff will be challenging but extremely motivating. Throughout this practicum there will be opportunities arising to monitor changes and improvements. Additionally I have the distinct pleasure of evaluating my soon to be "practicum infant" in the Developmental Follow Up Clinic after discharge. This will provide an opportunity for a longitudinal observation. The ultimate goal is to strengthen the relationship of the infant with his/her parents.

The AP will help me to enhance my observations and be able to impart my findings to minimize stressful situations with the infant and develop a family centered atmosphere. The infant's development and neurologic organization can be enhanced through ongoing nurturing care. I feel that the following Kahil Gibran quote speaks very well of what we try to strive for with the NIDCAP practicum: "Progress lies not in enhancing what is, but in advancing toward what will be."

Sincerely,

Maureen Rinehimer, PT, MS, MHS

(E I Certified)

Dear Editors,

The Developmental Observer is a triumph. I enjoyed the spring edition very much -interesting, informative and highly readable. I hope all my trainees are signed up for it, if not they are missing out. I know how much work (well probably I don't!) this must have taken and you should be very proud of the result.

Inga Warren, Dip COT, MSc 
Center for Excellence in Developmental and Related Disabilities. She is on the faculty for medical, nursing, therapy and other professional students with a goal of teaching family centered perspectives, particularly for children with disabilities and their families. Tracy is also a course facilitator for Ethics in Health Professions and is the Family Centered Care Consultant at the Children's Hospital in Denver. As a professional advocate, she is a master of facilitating dialogue between families and hospital systems to improve collaboration and resolve differences. Each of these important positions provides opportunities for influencing systems and culture change. Her leadership has been instrumental in a shift of the entire hospital's environment, policies and procedures toward family centered care.

Tracy's trademark is her bright smile regardless of personal or professional adversity. Recently she was hiking in the Colorado mountains and suffered a painful snakebite, which caused her to become quite ill. However, she quickly returned to work, which is her passion, with her ever-present smile and positive attitude. Tracy's experiences with her daughter Hayley have shaped the person she is today. Although Hayley had a number of challenging outcomes from her difficult start in life, Tracy always focused on Hayley's triumphs and individual capabilities rather than her disabilities. Tracy learned the best of life from Hayley and she applies those lessons to her work with individuals with disabilities and their families. Due to her unique personal experiences Tracy realizes that she has a special "insider" perspective and looks forward to sharing her vast knowledge base with the NFI Board. She feels the NFI will provide a broader range of opportunities to help others understand the strengths and challenges of having a baby in an NICU.

Both Vicky and Tracy have crossed paths in their professional and sometimes personal lives with Dr. Joy Browne, whose respect for each of them cannot be measured. If you want heart, soul, and a deep knowledge in support of babies and their families, Vicky and Tracy are the people you want on your side. The NFI Board is fortunate to have such dynamic and invested individuals join the effort in encouraging the implementation of developmental and family centered care. Their contributions and consultation will assure the ongoing quality of the Newborn Individualized Developmental Care and Assessment Program (NIDCAP) approach in all intensive and special care nurseries around the world.

\section{SUPPORTING FAMILIES Continued from page 13}

assumptions of caregivers, just as a thoughtful understanding of the synactive theory and its implications is far more important than any single positioning aid or nursery furnishing. NIDCAP professionals will find any of the references listed immediately to the right, but especially the introductory chapters in Cassidy and Shaver's (2008) second edition, are wonderful guides to the vast world of attachment literature. As caregivers grasp and integrate these principles, they will be even more equipped to support relationship and brain development in the most fragile infants and their families.
References:

1. Als H.Toward a synactive theory of development: promise for the assessment and support of infant individuality. Infant Mental Health Journal. 1982; 3, 229-243.

2. Cassidy J, Shaver PR. Handbook of Attachment, Second Edition. New York: Guilford Press; 2008.

3. Bowlby J. Attachment, Second Edition. New York: Basic Books; 1982.

4. Karen R. Becoming Attached: First Relationships and How They Shape Our Capacity to Love. New York: Oxford University Press; 1998.

5. Lieberman A.F, Van Horn P. Psychotherapy with Infants and Young Children: Repairing the Effects of Stress and Trauma on Early Attachment. New York: Guilford Press; 2008.

6. Als H, Lawhon g, Duffy FH, McAnulty GB, Gibes-Grossman R, Blickman JG. Individualized developmental care for the very low-birth-weight preterm infant: Medical and neurofunctional effects. Journal of the American Medical Association. 1994; 272, 853-858.

7. Als H, Duffy FH, McAnulty GB, Rivkin MJ, Vejapeyam S, Mulkern RV, Warfield SK, Huppi PS, Butler SC, Conneman N, Fischer C, Eichenwald EC. Early experience alters brain function and structure. Pediatrics. 2004; 113, 846-857.

8. Cozolino K. The Neuroscience of Human Relationships: Attachment and the Developin Social Brain. New York: Norton; 2006.

\section{CURRENT DEVELOPMENTAL RESEARCH Continued from page 14}

\section{References:}

1. Kramer MS, Aboud F, Mironova E, Vanillovich I, Platt RW, Matush L, Igumnov S, Fombonne E, Bogdanovich N, Ducruet T, Collet JP, Chalmers B, Hodnett E, Davidovsky S, Skugarevsky,O, Trofimovich O, Kozlova L, Shapiro S. Breastfeeding and child cognitive development:new evidence from a large randomized trial. Archives of General Psychaitry. 2008; 65 (5): 578-84.

2. Baby Friendly Initiative, http://www.babyfriendly.org accessed June 2008

3. Wechsler Abbreviated Scales of Intelligence (WASI), 1999, Harcourt Assessment Inc http://www.harcourtassessment.com accessed June 2008.

4. Vohr BR, Poindexter BB, Dusick AM, McKinley LT, Wright LL, Langer JC, Poole WK. Beneficial effects of breast milk in the neonatal intensive care unit on the developmental outcome of extremely low birth weight infants at 18 months of age. Pediatrics. 2006; 118 (1): e115-123.

5. Bayley N, 2001, Bayley Scales of Infant Development-II, The Psychological Corporation, http://www.harcourtassessment.com accessed June 2008.

6. Feldman R, Eidelman AI. Direct and indirect effects of breast milk on the neurobehavioral and cognitive development of premature infants. Developmental Psychobiology. 2003; 43 (2): 109-119.

7. Lucas A, Cole TJ. Breast milk and neonatal necrotizing enterocolitis. Lancet. 1990; 336: 1519-1523.
8. Pregnancy Risk Assessment Monitoring System (PRAMS): Methodology. Available at http://www. cdc.gov/prams/methodology.htm accessed January 2008.

9. Colaizy TT, Morriss FH. Positive effect of NICU admission on breastfeeding of preterm US infants in 2000 to 2003. Journal of Perinatology. 2008; March: 1-6.

10. Warren I, Tan GC, Dixon P, Ghaus K. Breast feeding success and early discharge for preterm infants: the result of a dedicated breast feeding programme. Journal of Neonatal Nursing. 20006 (2): 43-48.

11. Profit J, Zupancic JA, McCormick MC, Richardson DK, Escobar GJ, Tucker J, TarnowMordi W, Parry G._Moderately premature infants at Kaiser Permanenta medical care Program in California are discharged home earlier than their peers in Massachusetts and the United Kingdom. Archives of Disease in Childhood, Fetal Neonatal Edition. 2006; 91 : F245-F250.

12. Nyqvist KH. Early attainment of breastfeeding competence in very preterm infants Acta Paediatrica. 2008; 97: 776-781.

13. Sisk PM, Lovelady CA, Dillard RG, Gruber KJ. Lactation counseling for mothers of very low birthweight infants: Effect on maternal anxiety and infant intake of human milk. Pediatrics. 2006; 117 (1): e67-e75.

14. Kavanaugh K, Meier P, Zimmermann B, Mead L. The rewards outweigh the efforts: breastfeeding outcomes for mothers of preterm infants. Journal of Human Lactation. 2008; 31 (1): $15-21$. 


\section{SUBSCRIBE TODAY!}

\section{Developmental

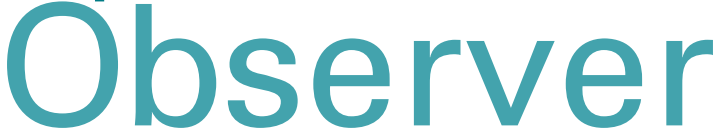

The Official Newsletter of the NIDCAP ${ }^{\circledR}$ Federation International

We invite you to subscribe by going to www.nidcap.org and selecting Subscribe on the NFI website.

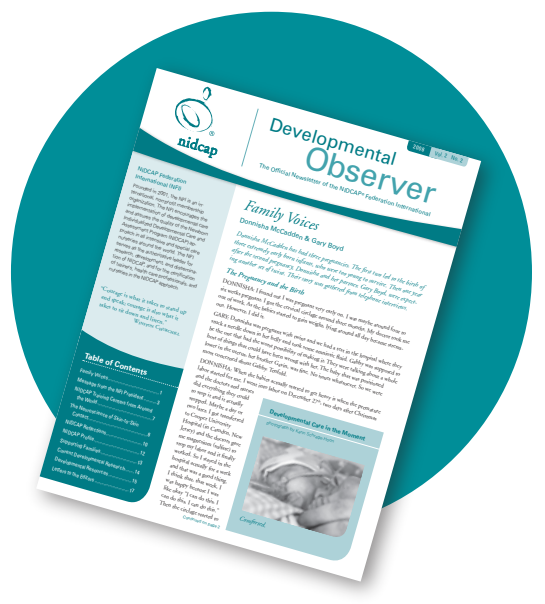

Subscription Period: 1 Year $(\$ 15) \quad 2$ Years $(\$ 25) \quad 3$ Years $(\$ 35)$

\section{NIDCAP Federation International Board Officers, Members and Staff}

President

Heidelise Als, PhD

NIDCAP Senior Master Trainer

APIB Master Trainer

Director, National NIDCAP

Training Center

email: heidelise.als@childrens.

harvard.edu

Vice President

gretchen Lawhon, RN, PhD

NIDCAP Master Trainer

Director, Mid-Atlantic NIDCAP

Center

email: Lawhon-gretchen@

cooperhealth.edu

Secretary

Deborah Buehler, PhD

NIDCAP Master Trainer

APIB Trainer

West Coast NIDCAP and APIB

Training Center

email: deborahbuehler@comcast.net

TrEAsUrer

Gloria McAnulty, PhD

National NIDCAP Training Center

email: gloria.mcanulty@childrens.

harvard.edu
Assistant Secretary

Sandra Kosta, BA

National NIDCAP Training Center

email: sandra.kosta@childrens.

harvard.edu

\section{James M. Helm, PhD}

NIDCAP Senior Trainer

Director, Carolina NIDCAP

Training Center

email: jimhelm@med.unc.edu

Tracy Price-Johnson, MA

Faculty at UCDHSC and

The Family Centered Care

Consultant at The Children's

Hospital in Colorado

email: Price-Johnson.Tracy@

tchden.org

Roger Sheldon, MD

Co-Director, Sooner NIDCAP

Training Center

email: roger-sheldon@ouhsc.edu

\section{Jacques Sizun, MD}

Director, French NIDCAP Center email: Jacques.sizun@chu-brest.fr

\section{Karen Smith, RNC, MEd}

NIDCAP Senior Trainer

St. Luke's Regional Medical Center email: smithka@s/rmc.org

Kathleen VandenBerg, PhD

NIDCAP Master Trainer

Director, West Coast NIDCAP and

APIB Training Center

email: kavandenberg@yahoo.com

\section{Victoria Youcha, EdD}

Child Development Specialist

Children's Medical Associates

Alexandria, VA

email:vyoucha@gmail.com

\section{David Wahl}

Director of Development and

Administration

email: nfidirector@nidcap.org 
by order of establishment

National NIDCAP Training Center

Brigham and Women's Hospital and

Children's Hospital Boston

Boston, Massachusetts USA

Contact: Sandra M. Kosta, BA

email: sandra.kosta@childrens.harvard.edu

\section{Sooner NIDCAP Training Center}

University of Oklahoma Health Sciences

Center, Oklahoma City, Oklahoma USA

Co-Director and Contact:

Laurie Mouradian, ScD, OTR/L

email: laurie-mouradian@ouhsc.edu

\section{Carolina NIDCAP Training Center}

WakeMed

Raleigh, North Carolina USA

Director and Contact:

James M. Helm, PhD

email: jimhelm@med.unc.edu or

jhelm@wakemed.org

\section{Colorado NIDCAP Center}

University of Colorado, Department of

Pediatrics at The Children's Hospital

Denver, Colorado USA

Director and Contact:

Joy V. Browne, PhD, CNS

email: browne.joy@tchden.org

\section{West Coast NIDCAP and APIB}

Training Center

San Francisco, California USA

Director and Contact:

Kathleen VandenBerg, PhD

email: vandenbergk@peds.ucsf.edu

\section{St. Luke's NIDCAP Center}

St. Luke's Regional Medical Center

Boise, Idaho USA

Contact: Karen M. Smith, RNC, BSN, MEd email:smithka@s/rmc.org

\section{Mid-Atlantic NIDCAP Center}

The Children's Regional Hospital at

Cooper University Hospital

Camden, New Jersey USA

Director and Contact:

gretchen Lawhon, RN, PhD

email: lawhon-gretchen@cooperhealth.edu

\section{Scandinavian NIDCAP Center,} Lund and Stockholm, Sweden

Astrid Lindgren Children's Hospital, Stockholm; Children's Hospital, Lund University Hospital, Lund and Department of Pediatrics, Borås Hospital

Contact: Ann-Sofie Gustafsson, RN, BSN email: nidcap@karolinska.se

\section{French NIDCAP Center, Brest, France} Medical School, Université de Bretagne Occidentale and University Hospital

Brest, France

Co-Director and Contact:

Nathalie Ratynski, MD

email: nathalie.ratynski@chu-brest.fr

\section{Sophia NIDCAP Training Center,}

Rotterdam, The Netherlands

Erasmus MC-Sophia, Children's Hospital

Rotterdam, The Netherlands

Co-Director and Contact:

Monique Oude Reimer, RN

email: nidcap@eramusmc.nl

\section{Centro Latinoamericano NIDCAP}

Fundación Dr. Miguel Margulies

Buenos Aires, Argentina

Director and Contact:

Maria Costanza Margulies

email: conicerullo@gmail.com or

basso.grace@gmail.com
UK NIDCAP Training Centre at St. Mary's

St. Mary's NHS Trust

London, England

Director and Contact:

Inga Warren, Dip, COT, MSc

email: inga.warren@imperial.nhs.uk

University of Illinois Medical Center at Chicago (UIMCC) NIDCAP Training Center Women's and Children's Nursing Services University of Illinois Medical Center at Chicago

Chicago, Illinois USA

Contact: Jean Powlesland, RN, MS

email: jpowles/@uic.edu

The NIDCAP Training Center at

Connecticut Children's Medical Center

Connecticut Children's Medical Center

Hartford, Connecticut USA

Co-Director and Contact:

Dorothy Vittner, RN, MSN

email: dvittner@ccmckids.org

\section{NIDCAP Training and Research Center at Cincinnati Children's \\ Cincinnati Children's Hospital \\ Medical Center \\ Cincinnati, Ohio USA \\ Contact: Tammy Casper, MSN, RN \\ email: tammy.casper@cchmc.org}

The Brussels NIDCAP Training Center, Belgium

Department of Neonatology

Saint-Pierre University Hospital

Free University of Brussels

Brussels, Belgium

Contact: Delphine Druart, RN

email: ddruart@hotmail.com

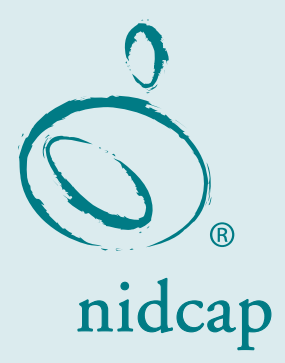

NIDCAP Federation

International (NFI)

www.nidcap.org

\section{Become a Member}

\section{of the NFI}

The NFI has expanded opportunities

for membership to Certified NIDCAP

Professionals, NIDCAP Trainees, and

Families of Premature Infants.

Please join us! For more information

and the online application form,

visit our website at:

www.nidcap.org. 